\title{
Hydraulic Permeability-Temperature Hysteresis for the Hydrophilic Membrane Prepared from the Block Copolymer Consisting of Polyamide and Polyoxyethylene Segments
}

\author{
Kazuhiko Hashimoto, Hiroshi Sumitomo, and Hiroo YAMAMORI
}

Faculty of Agriculture, Nagoya University, Furo-cho, Chikusa-ku, Nagoya 464, Japan

(Received July 19, 1986)

\begin{abstract}
Block copolymers composed of polyamide as the outer segment and polyoxyethylene as an inner segment were prepared by the anionic ring-opening polymerization of a bicyclic oxalactam, 8-oxa-6-azabicyclo[3.2.1] octan-7-one, activated with polyoxyethylene of different molecular weight having isocyanate groups at both chain ends. They were cast to the hydrophilic membranes, of which degree of hydration and hydraulic permeability $\left(K_{\mathrm{w}}\right)$ depended upon the length of the polyoxyethylene segment in the copolymers. The value of $K_{\mathrm{w}}$ for the membrane preheated in water at $50^{\circ} \mathrm{C}$ was lower than that for the original membrane in the temperature range from 25 to $45^{\circ} \mathrm{C}$. However the permeability was completely restored by aging in water at room temperature for a week. From an investigation on the behavior of water molecules in the membrane in terms of the thermal analyses, such a peculiar hysteresis can be presumed to come from the quick response of some structural transformation on heating and its slow relaxation on cooling.
\end{abstract}

KEY WORDS Block Copolymer / Polyamide / Polyoxyethylene / Hydrophilic Membrane / Water / Permeability / Relaxation / Hysteresis /

Recently a new block copolymer having hydrophilic polyamide and polyoxyethylene segments (1) was prepared by the anionic polymerization of a bicyclic oxalactam, 8oxa-6-azabicyclo[3.2.1] octan-7-one (abbreviated as BOL, 2), by the use of an isocyanateterminated polyoxyethylene (POE-NCO, 3) as an activator. The membrane produced from the resulting block copolymer exhibited high water permeability. ${ }^{1,2}$ The focus of the present article is mostly on a peculiar temperature dependence of hydraulic permeability for the membrane prepared from the block copolymer having a polyoxyethylene segment of relatively high molecular weight.

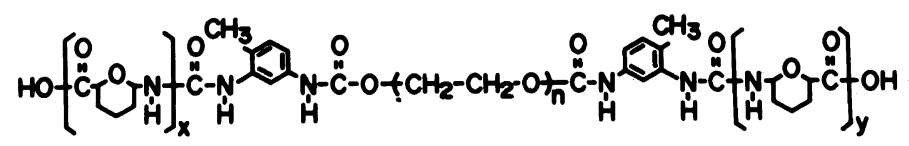

1

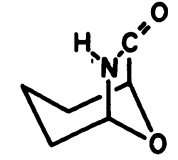

2<smiles>Cc1ccc(NC(=O)COCCCOC(=O)COCCCOC(=O)Nc2ccc(C)c(N=C=O)c2)cc1</smiles>

3 


\section{EXPERIMENTAL}

\section{Preparation of the Block Copolymer}

The anionic polymerization of $\mathbf{1}$ by the use of $\mathbf{3}$ as an activator was carried out in a high vaccum line by the same procedure as reported previously. ${ }^{1,2}$ In order to prepare 3 , of which molecular weight was higher than 8,000 , a large excess of tolylene-2,4-diisocyanate (TDI, 4) diluted with carbon tetrachloride was added to the corresponding polyoxyethylene glycol (POE-OH, 5) solution with vigorous stirring at $60^{\circ} \mathrm{C}$ in a high vacuum line. After the mixture was kept at $60^{\circ} \mathrm{C}$ for more than $70 \mathrm{~h}$, the resulting 3 was isolated and characterized as described in the previous paper. ${ }^{1}$

\section{Characterization of the Block Copolymer \\ Membrane}

The block copolymer membrane was obtained by casting from a $3 \%$ chloroformmethanol $(10: 1, \mathrm{wt})$ solution of its copolymer and drying at room temperature. The rate of water permeation through the membrane was measured under a pressure difference of 1$3 \mathrm{~kg} \mathrm{~cm}^{-2}$ at $15-50^{\circ} \mathrm{C}$ by using a commercial ultrafiltration cell, of which the effective membrane area was $13.9 \mathrm{~cm}^{2} .^{3-5}$ The wet membranes treated under various conditions were sealed in stainless steel capsules and subjected to DSC analyses using a PerkinElmer Model DSC-2 differential scanning calorimeter. The samples. were cooled at $10^{\circ} \mathrm{C} \min ^{-1}$ and kept at $-60^{\circ} \mathrm{C}$ for more than $30 \mathrm{~min}$ in order to freeze the contained freezable water molecules, and subsequently heated at $5^{\circ} \mathrm{C} \mathrm{min}^{-1}$ from $-60^{\circ} \mathrm{C}$ to $+17^{\circ} \mathrm{C}^{6}$

\section{RESULTS AND DISCUSSION}

\section{Preparation of the Block Copolymer}

First the isocyanate-terminated polyoxyethylene (3) of a different molecular weight from 1380 to 20,500 with narrow distribution was prepared from $\mathbf{4}$ and $\mathbf{5}$ as summarized in Table I.

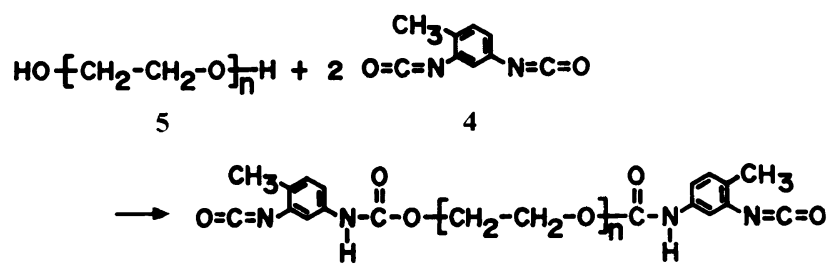

3

As described in the previous paper, ${ }^{1}$ 3, of which molecular weight is higher than 8,000 , is hard to prepare in dichloromethane at $40 \mathrm{C}$. Some of polyoxyethylene chains have been coupled with each other by the polyaddition reaction between the unreacted hydroxyl group in the polyoxyethylene chain (6) and the isocyanate group introduced in the other polyoxyethylene chain (7), because the poor solubility of 5 having high molecular weight caused an increase in the local concentration of the hydroxyl group in dichloromethane (see eq 2).

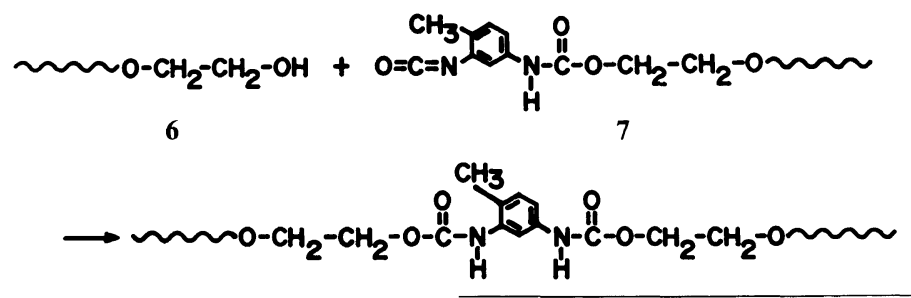


Table I. Preparation of various molecular weight polyoxyethylenes telechelated with isocyanate groups

\begin{tabular}{|c|c|c|c|c|c|c|c|c|c|c|}
\hline \multicolumn{2}{|c|}{ POE-OH } & \multirow{2}{*}{$\frac{\text { TDI }}{\mathrm{g}}$} & \multirow{2}{*}{$\frac{\left[_{\mathrm{TDI}}\right]^{\mathrm{a}}}{[\mathrm{POH}-\mathrm{OH}]}$} & \multicolumn{2}{|c|}{ Solvent } & \multirow{2}{*}{$\frac{\text { Temp }}{{ }^{\circ} \mathrm{C}}$} & \multirow{2}{*}{$\frac{\text { Time }}{\mathrm{h}}$} & \multirow{2}{*}{$\frac{\text { Yield }^{\mathrm{b}}}{\mathrm{g}}$} & \multirow{2}{*}{$\mathrm{N}^{\mathrm{c}, \mathrm{d}}$} & \multirow{2}{*}{$\bar{M}_{n}^{\mathrm{d}}$} \\
\hline $\bar{M}_{n}$ & g & & & & $\mathrm{ml}$ & & & & & \\
\hline 1,030 & 1.25 & 8.7 & 38 & $\mathrm{CH}_{2} \mathrm{Cl}_{2}$ & 60 & 39 & 96 & 0.96 & 1.99 & 1,380 \\
\hline 2,850 & 3.73 & 8.7 & 35 & $\mathrm{CH}_{2} \mathrm{Cl}_{2}$ & 50 & 38 & 96 & 3.06 & 2.01 & 3,250 \\
\hline 8,900 & 20.3 & 17.4 & 41 & $\mathrm{CH}_{2} \mathrm{Cl}_{2}$ & 120 & 38 & 24 & $\ldots^{e}$ & - & - \\
\hline 8,900 & 10.2 & 8.7 & 40 & $\mathrm{CCl}_{4}$ & 110 & 55 & 6 & $6.55^{f}$ & - & - \\
\hline 8,200 & 3.12 & 8.5 & 120 & $\mathrm{CCl}_{4}$ & 150 & 60 & 75 & 2.41 & 2.00 & 8,500 \\
\hline 10,500 & 3.90 & 8.6 & 120 & $\mathrm{CCl}_{4}$ & 200 & 60 & 70 & 2.73 & 1.87 & 11,500 \\
\hline 19,000 & 3.92 & 8.6 & 220 & $\mathrm{CCl}_{4}$ & 150 & 60 & 75 & 3.01 & 1.91 & 20,200 \\
\hline
\end{tabular}

${ }^{a}$ Mole ratio of TDI to POE-OH.

${ }^{b}$ Diethyl ether insoluble polymer.

c Average number of introduced isocyanate groups per fed polyoxyethylene chain before reaction with ethanol.

d Estimated from the content of terminal biscarbamic acid ester group determined by UV spectroscopy after the treatment with ethanol.

e Resinified.

' Some polyoxyethylene chains have coupled with each other by the polyaddition reaction.

Table II. Anionic polymerization of BOL with the use of various molecular weight polyoxyethylenes having terminal isocyanate groups as activators ${ }^{\mathrm{a}}$

\begin{tabular}{|c|c|c|c|c|c|c|c|c|}
\hline \multirow{2}{*}{$\frac{\mathrm{BOL}}{\mathrm{g}}$} & \multicolumn{2}{|c|}{ POE-NCO ${ }^{b}$} & \multirow{2}{*}{$\frac{\mathrm{Me}_{2} \mathrm{SO}}{\mathrm{ml}}$} & \multirow{2}{*}{$\frac{\text { Time }}{\mathrm{h}}$} & \multirow{2}{*}{$\frac{\text { Yield }^{\mathrm{c}}}{\mathrm{g}}$} & \multicolumn{2}{|c|}{ BOL unit in copolymer } & \multirow{2}{*}{$x^{\mathrm{d}}$} \\
\hline & $\bar{M}_{n}$ & $\mathrm{~g}$ & & & & Mole fraction & Weight fraction & \\
\hline 5.65 & 1,550 & 0.88 & 25 & 24 & 5.12 & 0.68 & 0.85 & 0.97 \\
\hline 4.50 & 3,250 & 0.98 & 16 & 1 & 3.88 & 0.53 & 0.77 & 0.93 \\
\hline 8.55 & 8,500 & 1.87 & 35 & 4 & 7.90 & 0.53 & 0.77 & 0.99 \\
\hline 8.75 & 11,500 & 1.91 & 35 & 7 & 8.12 & 0.58 & 0.80 & 0.85 \\
\hline 10.52 & 20,200 & 2.30 & 35 & 2 & 10.88 & 0.61 & 0.82 & 0.87 \\
\hline
\end{tabular}

a Polymerization conditions: potassium pyrrolidonate, $1 \mathrm{~mol} \%$ to $\mathrm{BOL}$; temperature, $25^{\circ} \mathrm{C}$.

b Isocyanate-terminated polyoxyethylene.

c Acetone insoluble polymer.

d Efficiency of block copolymerization estimated from the weight ratio of polyoxyethylene segment in the copolymer to POE-NCO fed initially.

Since the solubility of $\mathbf{5}$ in organic solvents depends upon its molecular weight and increases with temperature, not only the higher mole ratio of 4 to 5 but also the higher dilution and the higher reaction temperature should be desired for the preparation of $\mathbf{3}$ of high molecular weight. In the present system, 5 and larger excess of 4 were diluted with carbon tetrachloride at $60^{\circ} \mathrm{C}$ and then mixed with each other with vigorous stirring (see Table I). The resulting modified polyoxyethylenes were found to be terminated quantitatively with isocyanate groups at both chain ends without the simultaneous above-mentioned polyaddition reaction.

The block copolymers composed of polyamide and polyoxyethylene segments having different molecular weights were obtained in high yield by the anionic polymerization of 2 with the use of 3 having different molecular weights as activators in dimethyl sulfoxide $\left(\mathrm{Me}_{2} \mathrm{SO}\right)$ at $25^{\circ} \mathrm{C}$ (see Table II). The copolymer composition, which is expressed as the weight fraction, is kept almost constant by 
controlling the polymerization condition.

The efficiency of block copolymerization defined as a weight ratio of the polyoxyethylene consumed as an activator, to the polyoxyethylene fed, was high in every run. The macromolecular activators fed must have reacted almost quantitatively with lactam anions in the initiation step to give the corresponding acyllactam-type growing species, as well as common isocyanates.

The number average molecular weight of the block copolymer cannot be determined directly by the vapor-pressure or membrane osmometries owing to its high hygroscopicity. However it can be roughly presumed to increase with that of the macromolecular activator by taking into account that the anionic polymerization of $\mathbf{2}$ proceeds without side reactions at room temperature ${ }^{2,7-9}$ and that the composition of the resulting copolymers is almost constant.

As described in the previous article, ${ }^{1}$ the block copolymer containing a polyoxyethylene segment, of which molecular weight is lower than 3,000 , is soluble not only in $m$-cresol, trifluoroethanol, hexafluoroisopropanol, dimethyl sulfoxide, and chloroform-methanol $(10: 1$, wt) but also in chloroform, $N, N$-dimethylformamide, and pyridine. But the relatively high molecular weight block co- polymer prepared in the present system was insoluble in the latter solvents, just as was the high molecular weight homopolymer of 2 . So, the block copolymer was cast to the membrane from its chloroform-methanol solution as well as the homopolymer of 2 .

The microstructure of the resulting membrane is of interest, because of the remarked differences in the properties between the polyamide and polyoxyethylene segments. The polyamide chain should be more rigid than that of the polyoxyethylene not only due to the molecular skeleton but also due to the intermolecular interaction through the hydrogen bond between the amide groups. The rigidity in the former chains can also be presumed from the fact that the optically active polyamide is apt to form a double-stranded $10_{3}$ helix. ${ }^{10}$ From the additivity of the cohesive energy densities of the constituent elements, ${ }^{11-13}$ the solubility parameter of the former was calculated to be 13.8 , which is higher than the latter one (10.5). ${ }^{14}$ These values are related to the difference in the solubility between them as described in the previous paper. ${ }^{1}$ In addition, the crystallinity of the former, which can be regarded as a random copolymer composed of the enantiomeric repeating units, should be lower than that of the latter ${ }^{15}$ formed by a relatively

Table III. Water Permeability for membranes prepared from the block copolymers composed of polyamide and polyoxyethylene.segments ${ }^{\mathrm{a}}$

\begin{tabular}{|c|c|c|c|c|c|}
\hline \multicolumn{2}{|c|}{$\begin{array}{l}\text { Polyoxyethylene segment in } \\
\text { block copolymer }\end{array}$} & \multirow{2}{*}{$\begin{array}{l}\text { Degree of } \\
\text { hydration }^{b}\end{array}$} & \multirow{2}{*}{$\frac{\text { Thickness }^{\mathrm{c}}}{\mu \mathrm{m}}$} & \multirow{2}{*}{$\frac{\text { Water flux }}{1 m^{-2} h^{-1}}$} & \multirow{2}{*}{$\frac{K_{\mathrm{w}} \times 10^{10}}{\mathrm{~mol} \mathrm{cm^{-1 }} \mathrm{s}^{-1} \mathrm{~atm}^{-1}}$} \\
\hline $\bar{M}_{n}$ & Weight fraction & & & & \\
\hline - & $0^{\mathrm{d}}$ & 0.33 & 44 & 0.069 & 2.3 \\
\hline 2,850 & 0.23 & 0.47 & 72 & 0.15 & 8.4 \\
\hline 8,200 & 0.23 & 0.54 & 106 & 0.17 & 14.3 \\
\hline 10,500 & 0.20 & 0.58 & 118 & 0.24 & 23.3 \\
\hline 19,000 & 0.19 & 0.58 & 115 & 0.19 & 16.8 \\
\hline
\end{tabular}

a Measured under the pressure difference of $2 \mathrm{~kg} \mathrm{~cm}^{-2}$ at $25^{\circ} \mathrm{C}$.

b Volume fraction of water in membrane.

c In wet state.

d Homopolymer prepared from BOL. 
simple repeating unit. From the above discussion, the resulting membrane can be speculated to have a kind of microphase-separated structure, although its direct observation has not been attempted yet.

\section{Hydraulic Permeability of the Block Copolymer Membrane}

The degree of hydration of the block copolymer membrane seems to increase with the length of the polyoxyethylene segment in the copolymer and come close to 0.58 as shown in Table III. This fact may be mainly influenced by the size and/or shape of the microphaseseparated structure in the copolymer membrane, since the composition of the copolymer used is almost constant as mentioned already.

The water flux for the membrane was measured under a pressure difference of $1-3 \mathrm{~kg}$ $\mathrm{cm}^{-2}$ at $25^{\circ} \mathrm{C}$ and the hydraulic permeability, $K_{\mathrm{w}}$, was calculated by eq $3 .{ }^{16,17}$

$$
J_{\mathrm{w}}=K_{\mathrm{w}} \Delta p / \Delta x
$$

where $J_{\mathrm{w}}$ and $\Delta p / \Delta x$ are the water flux and pressure gradient, respectively. As expected from the high water content, ${ }^{18}$ the value of $K_{\mathrm{w}}$ for the membrane obtained from the block copolymer containing the high molecular

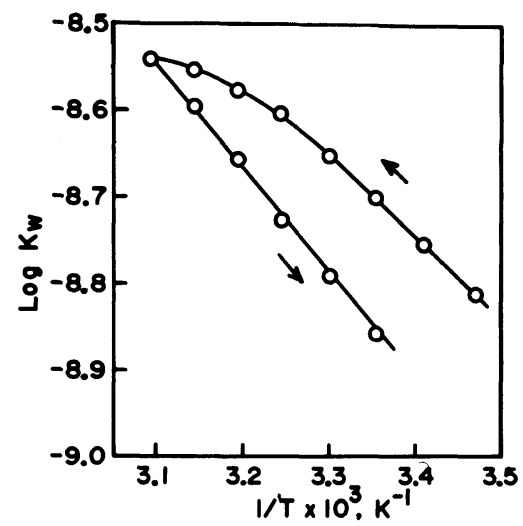

Figure 1. Hydraulic permeability-temperature hysteresis in the block copolymer membrane composed of polyamide and polyoxyethylene segments (weight fraction of the polyamide segments, $0.82 ; \bar{M}_{n}$ of polyoxyethylene segment, 19,000). weight polyoxyethylene segment was much higher than that for the homopolymer membrane from 2 . However some scatter was observed in the effect of the length of the polyoxyethylene segment on the permeability. The formation process of the block copolymer membrane using the mixed solvent can be presumed to be influenced by some factors, which cannot be controlled sufficiently under the present experimental conditions.

The most interesting result in this article, the hydraulic permeability-temperature hysteresis, was found during the determination of the water flux for the copolymer membrane in the temperature range from 15 to $50^{\circ} \mathrm{C}$ every five degrees. As shown in Figure 1, the value of $K_{\mathrm{w}}$ for the membrane preheated in water at $50^{\circ} \mathrm{C}$ was lower than that for the original membrane at every temperature in the range from 25 to $45^{\circ} \mathrm{C}$. However the permeability was completely restored by aging in water at room temperature for a week. Such a peculiar $K_{\mathrm{w}}$ temperature hysteresis was clearly observed especially for the membrane prepared from the copolymer having relatively high molecular weight polyoxyethylene segment. Therefore a detailed investigation was carried out on the copolymer composed of the longest segments in Table II.

It is also noteworthy that the hysteresis

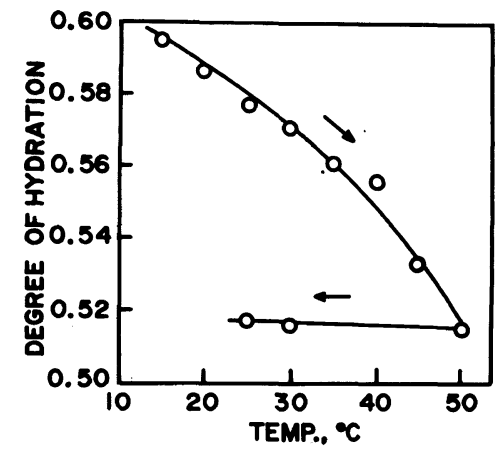

Figure 2. Degree of hydration-temperature hysteresis in the block copolymer membrane composed of polyamide and polyoxyethylene segments (copolymer composition and segment lengths are the same as in Figure 1). 
behavior was accompanied by a reversible change of the degree of hydration in the membrane (see Figure 2). Thus the degree of hydration decreased with the rise of temperature in the range from 15 to $50^{\circ} \mathrm{C}$. The value for the membrane preheated in water at $50^{\circ} \mathrm{C}$ was independent of the temperature in the range from 25 to $50^{\circ} \mathrm{C}$ and lower than that for the original membrane below $50^{\circ} \mathrm{C}$. In addition, the degree of hydration was restored by aging in water at room temperature for a week as well as permeability. The degree of hydration for the homopolymer of $\mathbf{2}$ is known to be independent of the surrounding temperature in the range from 25 to $45^{\circ} \mathrm{C}^{19,20}$ Therefore the hysteresis should have some correlation with the change of the adsorption mode of water molecules in the copolymer membrane.

\section{Thermal Analysis of Water Molecules in the Block Copolymer Membrane}

The differential scanning calorimetry is known to be useful to determine the adsorption behavior of water molecules in polymer membranes and gels. ${ }^{1,6,21-26}$ To discuss the $K_{\mathrm{w}}$-temperature hysteresis from this point of view, the wet block copolymer membranes treated under various conditions were thermally analyzed. All samples were heated at $5^{\circ} \mathrm{C} \mathrm{min}^{-1}$ from -60 to $+17^{\circ} \mathrm{C}$ after keeping at $-60^{\circ} \mathrm{C}$ in order to freeze the contained freezable water molecules.

As shown in Figure 3(A), two broad endothermic peaks emerged around -5 and $+2{ }^{\circ} \mathrm{C}$ for the unpreheated original membrane, of which the water content was $1.0 \mathrm{~g}$ perg dry polymer. They should be due to the fusion of frozen water. As described previously, ${ }^{1}$ the broad peaks observed in the present system suggest the existence of loosely-bound water probably in the region of the polyoxyethylene domain or boundary regions among the polyamide and polyoxyethylene domains. When the membrane was preheated in water at $50^{\circ} \mathrm{C}$ for only $1 \mathrm{~min}$ and subjected to the

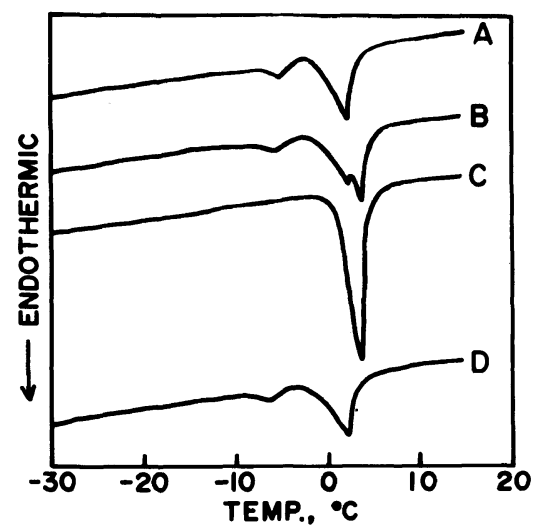

Figure 3. Influence of preheating on the fusion of water in the wet block copolymer membrane composed of the polyamide and polyoxyethylene segments (copolymer composition and segment lengths are the same as in Figure 1). Water content, $1.0 \mathrm{~g}$ per gram of the dry polymer; measured by heating at $5^{\circ} \mathrm{Cmin}^{-1}$ from $-60^{\circ} \mathrm{C}$ to $+17^{\circ} \mathrm{C}$ after being kept at $-60^{\circ} \mathrm{C}$ for more than $30 \mathrm{~min}$. Treatment of the membrane prior to the DSC measurement: A, original; $\mathrm{B}$, heated at $50^{\circ} \mathrm{C}$ for $1 \mathrm{~min}$; $\mathrm{C}$, heated at $50^{\circ} \mathrm{C}$ for $1 \mathrm{~h} ; \mathrm{D}$, heated at $50^{\circ} \mathrm{C}$ for $1 \mathrm{~h}$ followed by remaining at room temperature for 7 days.

thermal analysis, the intensities of both broad peaks were found to be reduced and the other sharp endothermic peak emerged around $+3^{\circ} \mathrm{C}$ (Figure 3(B)). After preheated in water for $1 \mathrm{~h}$, the former drastically disappeared and the latter was strengthened (Figure 3(C)). This means that the freezable loosely-bound water in the membrane was converted into normal water during the preheating. Some participation mode of water molecules in the polar sites including amide and ether groups through the inter- and intramolecular hydrogen bonds must decrease at high temperature.

Another noteworthy point concerns the peak intensity. The sharp peak in the thermogram for the preheated membrane was significantly greater than the sum of the broad peaks for the unpreheated one. Therefore the amount of the non-freezing water in the membrane can be speculated to decrease by the preheating. For its quantitative estimation, the influence of preheating upon the heat of 


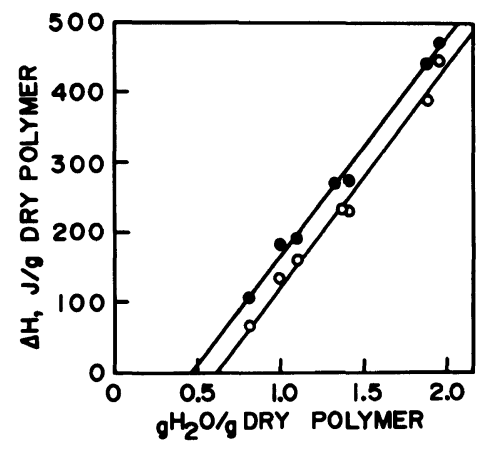

Figure 4. Relationships between heat of fusion of water around $0^{\circ} \mathrm{C}$ and its content in block copolymer membrane composed of the polyamide and polyoxyethylene segments (the copolymer composition and segment lengths are the same as in Figure 1). $O$, original membrane; 0 , measured after preheating the membrane in water at $50^{\circ} \mathrm{C}$ for more than $1 \mathrm{~h}$.

fusion of water in the block copolymer membranes with various water content was investigated as shown in Figure 4. From the relationships between the amounts of water adsorbed in the membranes and the heats of fusion of frozen water before and after the preheating, the amount of non-freezing water in the membrane was found to decrease from $0.61 \mathrm{~g}$ per $\mathrm{g}$ of the dry polymer to $0.46 \mathrm{~g}$ per $\mathrm{g}$ during the treatment. Such a conversion of a part of the non-freezing water to normal water should also be due to the decrease of the participation of water molecules into the membrane by the preheating.

After aging in water at room temperature for a week, the preheated membrane was subjected again to the same thermal analysis. As shown in Figure 3(D), the thermogram is quite different from that measured before the aging (Figure 3(C)), and quite similar with that for the original membrane (Figure 3(A)). This observation also corresponds to the already-mentioned restoration of the hydraulic permeability and the degree of hydration during aging.

The lower critical consolute temperature has been reported by some investigators ${ }^{27,28}$ to appear in the water-polyoxyethylene system and drop with the increase of molecular weight of the used polyoxyethylene. ${ }^{29}$ The polyoxyethylene segment telechelated with the polyamide segments in the block copolymer is essentially different from homopolyoxyethylene soluble in water, because the polyoxyethylene domain surrounded by the polyamide domains is swollen but not dissolved in water. Nevertheless the observed decrease of the participation of water molecules in the block copolymer membrane at higher temperature may be related to the phase separation behavior of homopolyoxyethylene in water.

Consequently the reversible variation of hydraulic permeability for the block copolymer membrane with the temperature can be speculated to come from some structural transformation mainly in the region of the polyoxyethylene domain or the boundary region among the polyamide and polyoxyethylene domains accompanied by a decrease of the participation of water molecules in the polar sites through inter- and intramolecular hydrogen bonds. The observed hydraulic permeability-temperature hysteresis must result from the quick response and slow relaxation of the transformation on heating and cooling, respectively.

\section{REFERENCES}

1. K. Hashimoto, H. Sumitomo, and H. Yamamori, Polym. J., 17, 679 (1985).

2. K. Hashimoto and H. Sumitomo, Makromol. Chem., Suppl., 12, 39 (1985).

3. H. Sumitomo, K. Hashimoto, and T. Ohyama, Polym. Bull., 1, 133 (1978).

4. K. Hashimoto and H. Sumitomo, Macromolecules, 13, 786 (1980).

5. M. Kawaguchi, T. Taniguchi, K. Tochigi, and A. Takigawa, J. Appl. Polym. Sci., 19, 2515 (1975).

6. H. Sumitomo and K. Hashimoto, "Contemporary Topics in Polymer Science," Vol. 4, W. J. Bailey and T. Tsuruta, Ed., Plenum, New York, N. Y., 1984, p 779.

7. K. Hashimoto and H. Sumitomo, Polym. J., 15, 547 (1983).

8. K. Hashimoto, H. Sumitomo, and M. Kawasumi, Polym. Bull., 11, 121 (1984).

9. K. Hashimoto, H. Sumitomo, and M. Kawasumi, 


\section{K. Hashimoto, H. Sumitomo, and H. Yamomori}

Polym. J., 17, 1045 (1985).

10. Z. Zheng, T. Yamane, T. Ashida, K. Hashimoto, and H. Sumitomo, Polym. J., 18, 973 (1986).

11. T. Matsuura, "Goseimaku-no-Kiso (Fundamentals of Synthetic Membranes)," Kitami-shobo, Tokyo, 1981.

12. C. M. Hansen and A. Beerbower, "Encyclopedia of the Chemical Technology," Supplement Volume, Wiley, New York, N. Y., 1977, p 889.

13. D. W. Van Krevelen, "Properties of Polymers," Elsevier, Amsterdam, 1976.

14. G. Allen, G. Gee, D. Mangaraj, D. Sims, and G. J. Wilson, Polymer, 1, 467 (1960).

15. H. Tadokoro, Y. Chatani, T. Yoshihara, S. Tahara, and S. Murahashi, Makromol. Chem., 73, 109 (1964).

16. K. S. Spiegler, Trans. Faraday Soc., 54, 1508 (1958).

17. O. Kedem and A. Katchalsky, J. Gen. Physiol., 45, 143 (1961).

18. H. Yasuda, C. E. Lamase, and A. Peterlin, J. Polym. Sci., $A-2$, 9, 1117 (1971).

19. T. Matsukura, T. Kinoshita, A. Takizawa, Y. Tsujita, H. Sumitomo, and K. Hashimoto, Kobunshi
Ronbunshu, 35, 803 (1978).

20. H. Sumitomo, K. Hashimoto, and T. Ohyama, Polym. Bull., 1, 635 (1979).

21. M. A. Frommer and D. Laucet, J. Appl. Polym. Sci., 16, 1295 (1972).

22. Y. Taniguchi and H. Horigome, J. Appl. Polym. Sci., 19, 2743 (1975).

23. M. Takami, F. Hori, R. Kitamaru, and Y. Ikada, Polym. Prepr., Jpn., 25, 426 (1976).

24. K. Nakamura, T. Hatakeyama, and H. Hatakeyama, Textile Res. J., 51, 607 (1981).

25. T. Hatakeyama, S. Hirose, and H. Hatakeyama, Makromol. Chem., 184, 1265 (1983).

26. K. Nakamura, T. Hatakeyama, and H. Hatakeyama, Polym. J., 18, 219 (1986).

27. G. N. Malcolm and J. S. Rowlinson, Trans. Faraday Soc., 53, 921 (1957).

28. F. E. Bailey and R. W. Callard, J. Appl. Polym. Sci., 1, 56 (1959).

29. P. Molyneux, "Water," Vol. 4, F. Franks, Ed., Plenum, New York, N. Y., 1975, p 625. 